\title{
A Mutation Unique in Serine Protease Inhibitors (Serpins) Identified in a Family with Type II Hereditary Angioneurotic Edema
}

\author{
Javier G. Ocejo-Vinyals, Francisco Leyva-Cobián, \\ and José L. Fernández-Luna
}

Servicio de Inmunología, Hospital Universitario Marqués de Valdecilla, Santander, Spain

\begin{abstract}
Background: Hereditary angioneurotic edema (HANE) is an autosomal dominant disease due to genetic alterations at the $\mathrm{Cl}$ inhibitor gene. Mutations within the $\mathrm{Cl}$ inhibitor gene are responsible for the molecular defect in type II HANE. Most of the dysfunctional proteins result from mutations involving the Arg-444 (the P-1 site of the reactive center) or amino acids $\mathrm{NH}_{2}$-terminal to the reactive center.

Materials and Methods: We have studied a Spanish family with type II HANE by using polymerase chain reaction (PCR) to amplify the exon eight of the $\mathrm{Cl}$ inhibitor gene. The purified 338-bp PCR product was subcloned and transformed into competent cells. After overnight cultures, we extracted the cloning vector from the positive colonies and sequenced both strands of the PCR
\end{abstract}

product from each patient and healthy members of the family.

Results: We show that affected individuals in this family have a missense mutation, changing an adenine to cytosine in the codon 445 . This substitution changes threonine at the $\mathrm{P}-\mathrm{l}^{\prime}$ site of the reactive center to a proline. This mutation generates a new restriction site, recognized by Bsi YI.

Conclusions: To our knowledge, this is the first molecular defect characterized in a Spanish family with type II HANE, and to date, this is the first reported mutation at the $\mathrm{P}-\mathrm{I}^{\prime}$ site of the reactive center in individuals with type II HANE. This new mutation located at the reactive center emphasizes once more time the enormous heterogeneity of this gene.

\section{INTRODUCTION}

Hereditary angioneurotic edema (HANE) is characterized by potentially life-threatening episodes of painless, nonpruritic, nonpitting edema, usually involving the face, upper airway, gastrointestinal tract and extremities. There are two variants of HANE $(1,2)$ : type I is characterized by low antigenic and functional levels of a normal $\mathrm{Cl}$ inhibitor protein. In type II, there are normal or increased antigenic levels of a dysfunctional mutant $\mathrm{Cl}$ inhibitor protein together with a reduced concentration of the functional protein.

The $\mathrm{Cl}$ inhibitor is a member of the serine protease inhibitors (SERPINS) (3) which shows

Address correspondence and reprint requests to: Javier G. Ocejo-Vinyals, Servicio de Inmunología, Hospital Universitario Marqués de Valdecilla, 39008-Santander, Spain. activity against the $\mathrm{Clr}$ and $\mathrm{Cls}$ subcomponents of the first component of complement (4-8). Moreover, it also inhibits kallikrein (9), activated Hageman factor (factor XIIa) and plasma thromboplastin antecedent (faxtor XIa or PTA) (10), plasmin (9), and tissue plasminogen activator $(11,12)$.

The Cl inhibitor shows structural and functional homologies with other human SERPINS such as $\alpha$-1-antitrypsin, antithrombin III, $\alpha-1$ antichymotrypsin, $\alpha$-2-antiplasmin, and heparin cofactor II (13-16). The reactive center of SERPINS mimics the substrate of the protease. In the $\mathrm{Cl}$ inhibitor protein, this reactive center is an Arg-Thr sequence at residues 444-445 (16). Binding of the protease cleaves the Arg-444 (P1) -Thr-445 (P-1') peptide bond and releases a small polypeptide molecule from the carboxy- 
terminal end of the $\mathrm{Cl}$ inhibitor. The sequences and lengths of SERPINS-reactive center are different $(14,16-19)$, and the P-1 site seems to be involved in determining the target protease specificity of individual SERPINS (16-19).

The complete nucleotide sequence of the human $\mathrm{Cl}$ inhibitor gene, which contains eight exons, has been recently determined (14,21). A significant feature of the intronic sequences is the increased frequency of $A l u l$ repeats. Another feature is that among normal individuals a restriction fragment length polymorphism can be observed after digestion of genomic DNA with HgiAI (14), which is sometimes useful for following the inheritance of normal and mutant alleles in HANE kindreds (22). In type I HANE the Alu 1 repeats predispose to intragenic breakpoints and unequal crossing-over (23), which together with partial deletions $(24,25)$, nonsense mutations (26), and other point mutations $(13,27)$ are responsible for this disease.

In type II HANE, the dysfunctional Cl inhibitor molecule usually has an amino acid change due to point mutations. Most often, at codon 444 (CGC) in the P-l site of the reactive center, point mutations changes Arg to His or Cys $(13,27)$. CG dinucleotides are the major methylated sequences in vertebrates and they are hotspots for mutations by deamination of 5-methylcytosine (22) and other mechanisms $(28,29,35)$. Other point mutations leading to dysfunctional $\mathrm{Cl}$ inhibitor molecules include Ala-434, Ala-436, and Val-432, among others $(13,20,27,30)$. In addition, a deletion of Lys-251 that results in acquisition of a new N-glycosilation site (31), a nucleotide insertion (32), and a cluster of mutations within exon 5 (33) has also been described.

Our study represents the first report of a single base mutation at codon 445 (P-1' site of the reactive center) that changes Thr to a Pro. This substitution generates also a new restriction site recognized by Bsi YI.

\section{MATERIALS AND METHODS}

\section{Patients}

We studied five patients and two unaffected members of one family (ages from 18 to 72 years) with type II HANE (Fig. lA). Consent informed was given to begin the study. The diagnosis of type II HANE was based on typical clinical symptoms and signs, normal antigenic $\mathrm{C} 1$ inhibitor plasma levels, low C4 levels as mea-

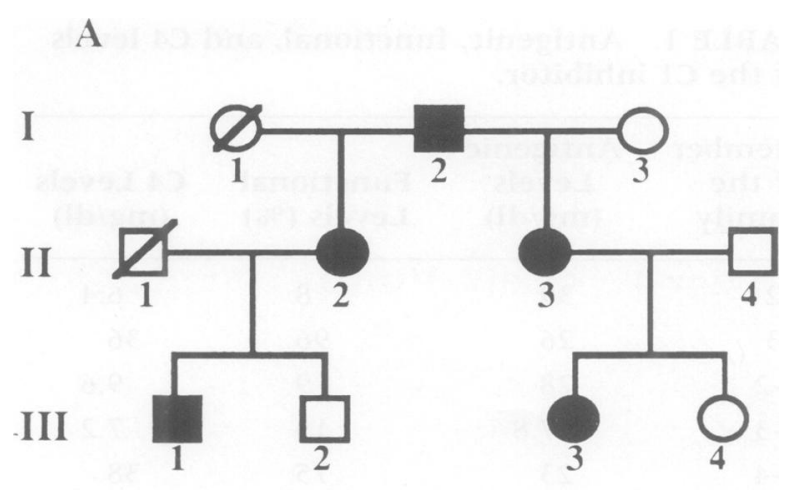

B

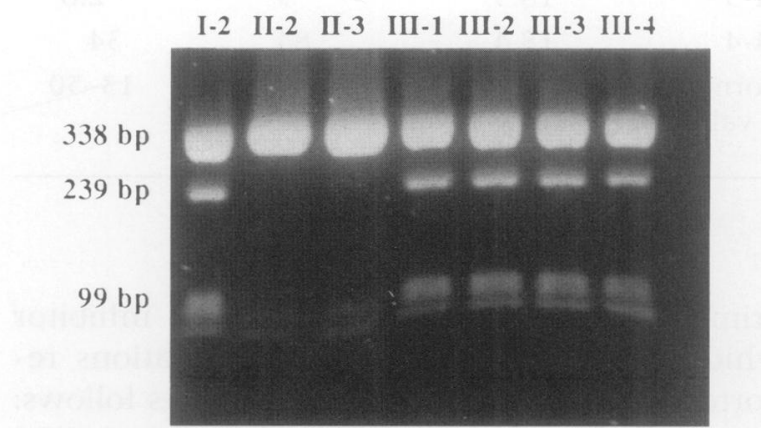

FIG. 1. Pedigree of the family with type II HANE and segregation of the BsiHKAI polymorphism

(A) The entire pedigree for the type II HANE family. Solid circles (females) and squares (males) represent affected individuals. Note the two marriages of the grandfather who had one affected daughter from each marriage. (B) Restriction fragment length polymorphism after digestion of the amplified exon eight with BsiHKAI (an isoschizomer of HgiAI). The normal PCR product is $338 \mathrm{bp}$ and the BsiHKAI restriction fragments of the mutant allele are $239 \mathrm{bp}$ and $99 \mathrm{bp}$ in size. Lanes are numbered as in Panel A.

sured by a nephelometric technique (Behring Nephelometer-Analyzer), and low or absent functional $\mathrm{Cl}$ inhibitor activity as measured by a chromogenic assay (Immunochrom; Immuno, Vienna, Austria). The analytical values of all the subjects investigated in this study are shown in Table 1 .

\section{PCR Amplification of Genomic DNA}

DNA was extracted from peripheral mononuclear cells of affected and healthy members of the family using standard procedures (34). The primers for the PCR analysis were designed from the published sequence (21). We selected intronic 
TABLE 1. Antigenic, functional, and C4 levels of the $\mathrm{Cl}$ inhibitor.

\begin{tabular}{lccc}
\hline $\begin{array}{l}\text { Member } \\
\text { of the } \\
\text { Family }\end{array}$ & $\begin{array}{c}\text { Antigenic } \\
\text { Levels } \\
\text { (mg/dl) }\end{array}$ & $\begin{array}{c}\text { Functional } \\
\text { Levels (\%) }\end{array}$ & $\begin{array}{c}\text { C4 Levels } \\
\text { (mg/dl) }\end{array}$ \\
\hline I-2 & 39 & 8 & 6.4 \\
I-3 & 26 & 96 & 36 \\
II-2 & 28 & 9 & 9.6 \\
II-3 & 17.8 & 15 & 7.2 \\
II-4 & 23 & 75 & 38 \\
III-1 & 24 & 10 & 7.3 \\
III-2 & 27 & 96 & 23 \\
III-3 & 18.3 & 3 & 2.8 \\
III-4 & 18.4 & 84 & 34 \\
Normal & $15-35$ & $>40$ & $13-50$ \\
values & & & \\
& & & \\
\hline
\end{tabular}

primers flanking exon eight of the $\mathrm{C} 1$ inhibitor which concentrates most of the mutations reported so far. The primer pair used is as follows: sense primer $\left(5^{\prime}\right.$-GCGAATTCTCATGCTGGCTTC TGACTCTGT - $\left.3^{\prime}\right)$, and antisense primer ( $5^{\prime}$-GCGA ATTCTCGCCCTAACCTGATCCTGCAG- $3^{\prime}$ ). The specific primer pair resulted in a 338-bp fragment after PCR amplification. Each PCR reaction contained $1 \mu \mathrm{g}$ genomic DNA, 30 pmol of each primer, $200 \mu \mathrm{M}$ dNTPs (Pharmacia, Uppsala, Sweden), $1.5 \mathrm{mM} \mathrm{MgCl}_{2}, 10 \mathrm{mM}$ Tris- $\mathrm{HCl} \mathrm{pH}$ 8.3, $50 \mathrm{mM} \mathrm{KCl}$, and 2,5 U Taq DNA polymerase (Promega, Madison, WI, U.S.A.) in a final volume of $50 \mu \mathrm{l}$. Reactions were carried out in a GeneAmp PCR System 9600 (Perkin Elmer, Norwalk, CT, U.S.A.) and the PCR conditions were as follows: $95^{\circ} \mathrm{C}$ for $2 \mathrm{~min}$ as initial denaturation and $95^{\circ} \mathrm{C}$ for $1 \mathrm{~min}, 55^{\circ} \mathrm{C}$ for $1 \mathrm{~min}$, and $72^{\circ} \mathrm{C}$ for $1 \mathrm{~min}$ for 30 cycles. Amplified products were run on $1 \%$ agarose gel and visualized by ethidium bromide staining.

\section{Cloning and Sequencing}

The 338-bp PCR product encompassing exon 8, was fractionated on a $1 \%$ low-melting point agarose gel and extracted using the Wizard PCR preps system (Promega Corp., Madison, WI). The purified product was ligated with the pCRIITAcloning vector (Invitrogen Corp., San Diego, CA, U.S.A.) and transformed into competent $\mathrm{DH} 5 \alpha$ cells (Life Technologies, Gaithersburg, MD, U.S.A.). DNA minipreps of $2-\mathrm{ml}$ overnight cul- tures were prepared with the Wizard minipreps DNA purification system (Promega) and sequenced using the Sequenase version 2.0 kit (United States Biochemical Corp., Cleveland, $\mathrm{OH}$, U.S.A.) in accordance with the manufacturer's instructions. Both strands were sequenced for each PCR product from at least three independent clones.

\section{RFLP Analysis}

The purified PCR products $(0.5-2 \mu \mathrm{g})$ were digested overnight in a total reaction volume of 30 $\mu \mathrm{l}$ with $10 \mathrm{U}$ of either BsiHKAI (an isoschizomer of HgiAI) (New England Biolabs GmbH, Schwalbach, Taunus, Germany), or BsiYI (BoehringerMannheim GmbH, Mannheim, Germany), using the manufacturer's buffer. Digestion products were fractionated on a $2 \%$ agarose gel and stained with ethidium bromide.

\section{RESULTS}

\section{RFLP Analysis of Alleles Coding for Dysfunctional Cl Inhibitor Protein}

The HgiAI restriction fragment length polymorphism has been previously used to follow inheritance of individual $\mathrm{Cl}$ inhibitor alleles in HANE kindreds and to identify those carrying abnormal genes (22). In order to carry out this family study, exon 8 was amplified by PCR using intronic primers flanking the exon. The amplified product (338 bp) was then digested to completion with BsiHKAI (an isoschizomer of HgiAI) and the resultant fragments (239 and $99 \mathrm{bp}$ ) resolved by agarose gel electrophoresis. As shown in Fig. 1B, the BsiHKAI RFLP is present in both patients (I-2, III-1, and III-3 are heterozygous, and III-2 and II-3 are homozygous for this polymorphism) and unaffected members (III-2, III-4) of the family, which makes this polymorphism to be not informative in this family.

\section{Nucleotide Sequence Analysis of the PCR Amplified Exon 8}

Most of the mutations affecting the $\mathrm{Cl}$ inhibitor gene are located within exon 8 , which encodes the reactive center of the protein. Exon 8 was amplified by PCR using primers flanking the entire exon, subcloned into a pCRIITA vector and sequenced from both ends.

The screening detected a missense mutation 


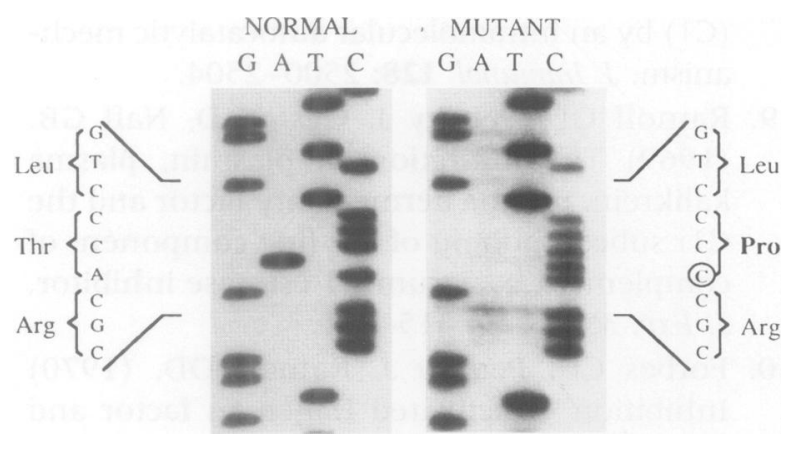

FIG. 2. DNA sequence of the PCR-amplified exon 8

On the left, partial sequence from a normal control. On the right, an A to $C$ change (marked with a circle) in a sample of an individual with type II HANE (I-2) which is identical to those seen in the other affected members of the family.

that substitutes an A to $C$ at nucleotide 16791 . The substitution was detected in all family members affected with type II HANE disease but not in any unaffected members (Fig. 2). This mutation changes Thr to a Pro at codon 445. The substitution of an A to $C$ creates a new BsiYI restriction site.

\section{Digestion of Amplified Exon 8 with BsiYI}

Digestion of the purified PCR product (338 bp) with BsiYI gave rise to two fragments with the expected sizes (200 and $138 \mathrm{bp}$ ), and we used this analysis to demonstrate the segregation of this mutation in the five affected members of the studied family (Fig. 3).

\section{I-2 II-2 II-3 III-1 III-2 III-3 III-4}

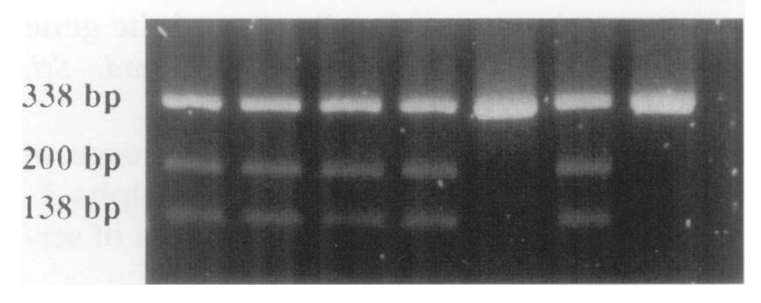

FIG. 3. BsiYI digestion analysis of PCR products

Digestion of the amplified exon 8 (338 bp) with BsiYI give rise to two fragments of 200 and $138 \mathrm{bp}$ in the affected individuals. Lanes are as in Fig. 1.

\section{DISCUSSION}

Type II HANE represents almost $15 \%$ from total HANE and is characterized by normal to elevated levels of $\mathrm{Cl}$ inhibitor protein in plasma, but with reduced functional activity $(1,2)$.

To date, mutations resulting in amino acid changes at the Pl site of the reactive center are the most frequent cause of type II HANE. Other substitutions located $5^{\prime}$ to the reactive center are also responsible for the defect. These substitutions seem to generate conformational changes affecting interactions of the $\mathrm{Cl}$ inhibitor with its targets.

The reactive center mutations occur in a CG dinucleotide, which has been demonstrated to be a hotspot for mutations, probably resulting from deamination of 5-methylcytosine to thymidine $(22,35)$.

Target protease specificity must be influenced by non-reactive-center residues, as many investigators have reported. Mutations that generate amino acids substitutions in the hinge region near the reactive center and in other regions of the protein also result in a dysfunctional $\mathrm{Cl}$ inhibitor molecule $(13,20,27-33)$. Substitutions of Arg-444 by His, Cys, Leu, and Ser at the reactive center of the $\mathrm{Cl}$ inhibitor molecule are the most frequent defects responsible for the dysfunctional protein. Similarly, replacement of Ala434 (P-12) by Glu, Val432 (P-14) by Glu, and Ala436 (P-10) by Thr also causes the dysfunction. This is probably due to conformational changes in the loop near the reactive center. All SERPINS have a P-12 Ala residue that seems to be critical for the conformational change that occurs during successful interactions between SERPINS and serine proteinases, and this codon is conserved among SERPIN genes (13).

The reactive center of serpins mimics the substrate of the protease. Recognition of this reactive-center peptide bond results in complex formation between the amino acid residue amino-terminal to this bond (the $\mathrm{Pl}$ residue) and the active-site of the protease. Proteases inactivated by the $\mathrm{Cl}$ inhibitor recognize the Arg444 (P1)Thr445 (P-1') dipeptide.

Here we report the first mutation involving the codon for Thr445, at the P-1' site of the reactive center, which is substituted by a Pro. This mutation leads to a new restriction site recognized by BsiYI. This new RFLP has never been observed among normal subjects and cosegregates with HANE in this family. The natural HgiAI polymorphism detected among normal in- 
dividuals has not been useful for following the inheritance pattern of the molecular defect in this family because there were healthy members with the HgiAI polymorphism.

The substitution of a Thr by a Pro may interrupt the secondary structure of the protein, originating conformational changes that disturb the interaction of the $\mathrm{Cl}$ inhibitor molecule with its substrates. Finally, it is worthwhile to emphasize the enormous heterogeneity of this gene, as other authors have reported $(13,27)$.

\section{ACKNOWLEDGMENTS}

We thank Fred S. Rosen (Harvard Medical School, Boston) and Santiago Rodríguez de Córdoba (CIB-CSIC, Madrid) for critical review of the manuscript. This work is partially supported by Fondo de Investigaciones Sanitarias Grants FIS-94/1415 and FIS-94/0933.

\section{REFERENCES}

1. Rosen FS, Charache P, Pensky J, Donaldson VH. (1965) Hereditary angioneurotic edema: Two genetic variants. Science 148: 957-958.

2. Rosen FS, Alper CA, Pensky J, Klemperer MR, Donaldson VH. (1971) Genetically determined heterogeneity of the $\mathrm{Cl}$ esterase inhibitor in patients with hereditary angioneurotic edema. J. Clin. Invest. 50: 2143-2149.

3. Carrell RW, Boswell DR. (1986) The superfamily of proteinase inhibitors. In: Barret A, Salvesen G (eds). Protease Inhibitors. Elsevier, Amsterdam, pp. 403-420.

4. Donaldson VH. (1961) Studies on the activation of a serum esterase with ether and its relationship to $C^{\prime} 1$ esterase. J. Clin. Invest. 40: 673-683.

5. Donaldson VH, Evans RR. (1961) Absence of an enzyme inhibitor in hereditary angioneurotic edema. J. Lab. Clin. Med. 58: 812.

6. Donaldson VH, Evans RR. (1963) A biochemical abnormality in hereditary angioneurotic edema: Absence of serum inhibitor in $C^{\prime} 1$-esterase. Am. J. Med. 35: 37-44.

7. Ziccardi RJ. (1982) A new role for Cl-inhibitor in hemostasis: Control of activation of the first component of human complement. J. Immunol. 128: 2505-2508.

8. Ziccardi RJ. (1982) Spontaneous activation of the first component of human complement
(Cl) by an intramolecular autocatalytic mechanism. J. Immunol. 128: 2500-2504.

9. Ratnoff OD, Pensky J, Ogston D, Naff GB. (1969) The inhibition of plasmin, plasma kalikrein, plasma permeability factor and the Clr subcomponent of the first component of complement by serum $\mathrm{Cl}$ esterase inhibitor. J. Exp. Med. 129: 315-331.

10. Forbes CD, Pensky J, Ratnoff OD. (1970) Inhibition of activated Hageman factor and activated plasma thromboplastin antecedent by purified serum $\mathrm{Cl}$ inactivator. J. Lab. Clin. Med. 76: 809-815.

11. Booth NA, Walker E, Maughan R, Bennett B. (1987) Plasminogen activator in normal subjects after exercise and venous occlusion: tPA circulates as complexes with $\mathrm{Cl}$ inhibitor and PAI-1. Blood 69: 1600-1604.

12. Bennett B, Croll A, Ferguson K, Booth NA. (1990) Complexing of tissue plasminogen activator with PAI-1, alpha 2-macroglobulin, and $\mathrm{Cl}$-inhibitor: Studies in patients with defibrination and a fibrinolytic state after electroshock or complicated labor. Blood 75: 671-676.

13. Donaldson VH. (1993) Cl-inhibitor and its genetic alterations in hereditary angioneurotic edema. Intern. Rev. Immunol. 10: 1-16.

14. Bock SC, Skriver K, Nielsen E, et al. (1986) Human $\mathrm{Cl}$ inhibitor: Primary structure, cDNA cloning, and chromosomal localization. Biochemistry 25: 4292-4301.

15. Davis III AE. (1988) Cl-inhibitor and hereditary angioneurotic edema. Annu. Rev. Immunol. 6: 595-628.

16. Salvesen GS, Catanese JJ, Kres LF, Travis J. (1985) Primary structure of the reactive site of human Cl-inhibitor. J. Biol. Chem. 260: 2432-2436.

17. Davis III AE, Whitehead AS, Harrison RA, et al. (1986) Human inhibitor of the first component of complement, $\mathrm{Cl}$ : Characterization of cDNA clones and localization of the gene to chromosome 11. Proc. Natl. Acad. Sci. U.S.A. 83: 3161-3165.

18. Huber R, Carrell RW. (1989) Implications of the three-dimensional structure of alpha-1antitrypsin for structure and function of serpins. Biochemistry 28: 8951-8966.

19. Travis J, Salvesen G. (1983) Human plasma proteinase inhibitors. Annu. Rev. Biochem. 52: 655-709.

20. Skriver K, Wikoff WR, Patston PA, et al. (1991) Substrate properties of $\mathrm{Cl}$ inhibitor 
Ma (alanine 434-glutamic acid). J. Biol. Chem. 266: 9216-9221.

21. Carter PE, Duponchel C, Tosi M, Fothergill JE. (1991) Complete nucleotide sequence of the gene for human $\mathrm{Cl}$ inhibitor with an unusually high density of Alu elements. Eur. J. Biochem. 197: 301-308.

22. Skriver K, Radziejewska E, Silbermann JA, Donaldson VH, Bock SC. (1989) CpG mutations in the reactive site of human $\mathrm{Cl}$ inhibitor. J. Biol. Chem. 264: 3066-3071.

23. Stoppa-Lyonnet D, Duponchel C, Meo T, et al. (1991) Recombinational biases in the rearranged $\mathrm{Cl}$ inhibitor genes of hereditary angioedema patients. Am. J. Hum. Genet. 49: 1055-1062.

24. Stoppa-Lyonnet D, Carter PE, Meo T, Tosi M. (1990) Clusters of intragenic Alu repeats predispose the human $\mathrm{Cl}$ inhibitor locus to deleterious rearrangements. Proc. Natl. Acad. Sci. U.S.A. 87: 1551-1555.

25. Ariga T, Igarashi $T$, Ramesh $N$, Parad $R$, Cicardi M, Davis III AE. (1989) Type I Cl inhibitor deficiency with a small messenger RNA resulting from deletion of one exon. $J$. Clin. Invest. 83: 1888-1893.

26. Frangi D, Cicardi M, Sica A, Colotta F, Agostoni A, Davis III AE. (1991) Nonsense mutations affect $\mathrm{Cl}$ inhibitor messenger RNA levels in patients with type I hereditary angioneurotic edema. J. Clin. Invest. 88: 755-759.

27. Donaldson VH, Bissler JJ. (1992) Cl inhibitors and their genes: An update. J. Lab. Clin. Med. 119: 330-333.

28. Aulak KS, Cicardi M, Harrison RA. (1990)

Contributed by K. F. Austen on June 27, 1995.
Identification of a new $\mathrm{Pl}$ residue mutation (444 ARG-Ser) in a dysfunctional Cl inhibitor protein contained in a type II hereditary angioedema plasma. FEBS. Lett. 266: 13-16.

29. Frangi D, Aulak KS, Cicardi M, Harrison RA, Davis III AE. (1992) A dysfunctional Cl inhibitor protein with a new reactive center mutation (ARG 444-Leu). FEBS. Lett. 301: $34-46$.

30. Levy NJ, Narayanaswamy R, Cicardi M, Harrison RA, Davis III AE. (1990) Type II hereditary angioneurotic edema that may result from a single nucleotide change in the codon for alanine-436 in the $\mathrm{Cl}$ inhibitor gene. Proc. Natl. Acad. Sci. U.S.A. 87: 265-268.

31. Parad RB, Kramer J, Strunk RC, Rosen FS, Davis III AE. (1990) Dysfunctional Cl inhibitor Ta: deletion of lys-251 results in acquisition of an N-glycosylation site. Proc. Natl. Acad. Sci. U.S.A. 87: 6786-6790.

32. Siddique $Z$, McPhaden AR, Whaley $K$. (1993) Cl inhibitor gene nucleotide insertion causes type II hereditary angio-edema. Hum. Genet. 92: 189-190.

33. Bissler JJ, Cicardi M, Donaldson VH, et al. (1994) A cluster of mutations within a short triplet repeat in the $\mathrm{Cl}$ inhibitor gene. Proc. Natl. Acad. Sci. U.S.A. 91: 9622-9625.

34. Sambrook J, Fritsch EF, Maniatis T. (1989) Molecular Cloning: A Laboratory Manual. Cold Spring Harbor University Press, Cold Spring Harbor, p. 9.17.

35. Cooper DN, Youssoufran H. (1988) The CpG dinucleotide and human genetic disease. Hum. Genet. 78: 151-155. 